\title{
Functional Polymer Composites Using Multiferroic Ceramic Nanofillers
}

\author{
Geunryeol Baek and Su Chul Yang
}

Department of Chemical Engineering (BK21 FOUR), Dong-A University, Busan, Korea 49315

\section{다강성 세라믹 나노충진재를 이용한 기능성 고분자 복합체}

\author{
백근렬, 양수철 ${ }^{\dagger}$ \\ 동아대학교 화학공학과 (BK21 FOUR 교육연구단)
}

(Received August 9, 2021; Accepted August 17, 2021)

\begin{abstract}
초록
Multiferroic materials exhibited more than one ferroic properties of piezoelectric, magnetostrictive, and magnetoelectric. Among the multiferroic materials, magnetoelectric (ME) materials coexisting ferroelectric and ferromagnetic properties has attracted great attention due to its unique applications such as energy harvesters, highly-sensitive magnetic sensors, actuators, memory devices. With the increase in demand of flexible and multifunctional electronic devices, polymer-based ME composites consisting of ferroelectric polymer matrix and ferromagnetic ceramic nanofillers have been developed by optimization of materials, structure, and process. In this review, we described research history and feasible applications for the polymer-based ME composites. We believe that the polymer-based ME composites can be a potential candidate for self-powered energy and sensing devices relevant to the fourth industrial revolution in the near future.
\end{abstract}

Keywords : Multiferroic, Magnetoelectric, Piezoelectric, Magnetostrictive, Polymer composites

†Corresponding Author: scyang@dau.ac.kr 


\section{1. 서론}

다강성 (multiferroic) 이란 강유전성 (ferroelectric), 강자성 (ferromagnetic), 강탄성 (ferroelastic) 중 두 가지 이상의 특성을 가지고 있어 발생하는 복합 특성 으로, 특히 강유전성과 강자성 특성을 동시에 발현하 는 자기전기 (magnetoelectric, $\mathrm{ME}$ ) 효과는 센서, 액 츄에이터, 에너지 하베스팅, 메모리 디바이스 등 다양 한 분야에 응용이 가능하다는 잠재력을 가지고 있어 많 은 연구가 활발히 진행되어 왔다. ${ }^{1)}$ 연구 초창기 자기 전기 물질의 개발은 $\mathrm{Cr}_{2} \mathrm{O}_{3}, \mathrm{BiFeO}_{3}(\mathrm{BFO})$ 와 같은 단일 상 (singe-phase)에서부터 출발하였으며, 대부분 단일 상 자기전기 물질의 경우 조성 자체의 내재적인 자기전 기 출력 전압이 낮을 뿐만 아니라 강자성 물질이 상자성 물질로 전이되는 퀴리 온도(Curie temperature)가 상 온보다 낮기 때문에 이를 응용하는데 제약으로 존재했 다. ${ }^{2-3)}$ 2000년 이후 압전 (piezoelectric) 특성과 자왜 (magnetostrictive) 특성을 가지고 있는 물질들을 복합 화 하여 자기전기 복합체 (ME composite)를 개발하였 고 이를 통해 높은 자기전기 특성을 확보하려는 연구가 진행되고 있다.

압전상과 자왜상을 복합화하여 개발한 자기전기 복합 체로부터 자기전기 (direct magnetoelectric, DME) 특 성과 역자기전기 (converse magnetoelectric, $\mathrm{CME}$ ) 특성을 얻을 수 있다. ${ }^{4)}$ 자기전기 특성이란 복합체에 외 부 자기장을 인가할 경우 자왜 재료의 기계적 변형이 발 생하게 되고, 물리적으로 접합 되어있는 압전 재료에 게 기계적 응력으로써 전달되어 압전 재료로부터 전압 이 유도되는 것을 의미한다. 이와 반대로 역자기전기란 복합체에 외부 전기장을 인가할 경우 역압전 (inverse piezoelectric) 효과가 발생하여 압전 재료의 기계 적 변형이 유도되고, 이는 동일하게 기계적 응력으로 써 자왜 재료에 전달되어 자왜 재료의 역자왜 (inverse magnetostrictive) 효과의 발생으로 인해 자화값이 변 하는 것을 의미한다. 자기전기 및 역자기전기 특성에 대 한 수식은 아래와 같이 정의된다.

$$
D M E=\frac{\text { Deformation }}{\text { Magnetic field }} \times \frac{\text { Electrical polarization }}{\text { Deformation }}
$$

$$
\text { CME }=\frac{\text { Deformation }}{\text { Electric field }} \times \frac{\text { Magnetization }}{\text { Deformation }}
$$

이러한 자기전기 복합체는 단일상 대비 상온에서 높 은 자기전기 출력전압을 나타내어 자기전기 특성을 활 용한 에너지 하베스팅 또는 고감도 센서에 관한 연구 가 집중되었으며, 자기전기 복합체의 초기 연구는 높 은 압전특성을 보이는 상과 높은 자화특성을 보이는 상 을 여러가지 구조로 복합화 하여 자기전기 특성을 향 상시켜 왔다. 상온에서 약 $600 \mathrm{pC} / \mathrm{N}$ 의 높은 압전 계 수 (piezoelectric coefficient, $\mathrm{d}_{33}$ )을 지니는 대표적인 압전 재료인 $\mathrm{Pb}\left[\mathrm{Zr}_{\mathrm{x}} \mathrm{Ti}_{1-\mathrm{x}}\right] \mathrm{O}_{3}$ (lead zirconate titanate, $\mathrm{PZT})$ 를 주로 사용하였는데, 체내에 축적될 경우 중독을 유발하는 납 $(\mathrm{Pb})$ 이 포함되어 있어 $\mathrm{BaTiO}_{3}(\mathrm{BTO}),(\mathrm{K}$, $\mathrm{Na}) \mathrm{NbO}_{3}(\mathrm{KNN})$ 및 $(\mathrm{Bi}, \mathrm{Na}) \mathrm{TiO}_{3}(\mathrm{BNT})$ 등과 같은 비 납계 압전 재료 (lead-free piezoelectric materials)를 사용하는 연구가 많이 진행되었다. ${ }^{5-6)}$ 자왜 재료의 경우 높은 자왜 계수 (Magnetostrictive coefficient, $\lambda$ )를 지 니는 Terfenol-D ( $\left.\mathrm{Tb}_{\mathrm{x}} \mathrm{Dy}_{1-\mathrm{x}} \mathrm{Fe}_{2}\right)$, Galfenol $\left(\mathrm{Fe}_{\mathrm{x}} \mathrm{Ga}_{1-\mathrm{x}}\right)$ 및 Metglas (FeSiB) 등을 이용하여 자기전기 복합체를 개발해 왔다. ${ }^{7-8)}$

최근 유연하면서도 다기능성을 갖는 디바이스에 대한 소비자들의 요구가 증대됨에 따라 압전 고분자를 이용 한 자기전기 복합체가 주목받고 있다. 대표적인 압전 고 분자는 poly(vinylidene fluoride) (PVDF)로 높은 유연 성, 가벼운 무게, 간단한 제작 공정, 생체적합성 등의 장 점을 지녀 웨어러블 디바이스로의 응용 가능성 또한 높 게 평가받고 있다. 그러나 앞서 언급한 PZT, BTO 등과 같은 압전 세라믹과 비교하였을 때 훨씬 낮은 압전 계수 $\left(\mathrm{d}_{33}=\sim 24 \mathrm{pC} / \mathrm{N}\right)$ 를 보여며, 결국 낮은 자기전기 출 력전압이 유도된다는 단점은 자기전기 고분자 복합체의 응용에 큰 제약이 되고 있다. 따라서 2010년 이후로 고 분자 기반의 자기전기 복합체로부터 높은 자기전기 출 력전압을 유도하기 위한 다양한 구조 및 공정 개발을 활 
발히 진행하고 있다. ${ }^{9-11)}$

자기전기 복합체 구조로는 압전 고분자 매트릭 스 내에 자왜 나노충진재가 포함된 3-0 미립자 구조 (particulate structure), 그리고 압전 필름과 자왜 필름 이 적층된 2-2 라미네이트 구조 (laminate structure) 두 가지로 분류될 수 있는데, 본 연구에서는 3-0 미립 자 구조 복합체 제작을 위한 재료, 자왜 나노충진재 구 조, 그리고 자기전기 복합체 필름 제작을 위한 공정 각 각의 개발에 대한 접근 방법을 소개하고, 마지막으로 자 기전기 복합체 필름의 에너지, 센서, 환경, 바이오 메디 컬 등 다양한 분야에서의 응용 방안에 대해 설명하고자 한다.

\section{2. 자기전기 고분자 복합체의 재료 개발}

\section{1. 압전 재료}

2010년 이후로 활발하게 연구되고 있는 고분자 기 반의 자기전기 복합체는PVDF계열을 주로 사용해 왔 으며, $\mathrm{PVDF}$ 고분자가 가지고 있는 $\mathrm{C}-\mathrm{H}$ 와 $\mathrm{C}-\mathrm{F}$ 의 수 소와 플루오린의 전기음성도 차이에 의해 각각 양전 하와 음전하를 띠게 되어 강한 쌍극자 모멘트 및 분극 을 형성함으로써 압전 특성이 발현된다. $\mathrm{PVDF}$ 는 $\mathrm{C}-\mathrm{H}$ 와 $\mathrm{C}-\mathrm{F}$ 의 배치 형태에 따라 $\alpha$ (알파), $\beta$ (베타), $\gamma$ (감 마), $\delta$ (델타) 등 다양한 결정상을 지닐 수 있는데, 이 들 중 all-trans (TTTT) 배치를 지니는 베타상이 가 장 높은 쌍극자 모멘트를 지니기 때문에 PVDF의 베 타상 분율을 향상시켜 자기전기 출력전압을 높이는 연 구가 많이 이루어지고 있다. ${ }^{12)} \mathrm{PVDF}$ 의 베타상 분율은 $\mathrm{PVDF}$ 매트릭스 내에 분산되는 자왜 나노충진재의 물리 적 형태 변경 또는 표면 개질을 통한 구조적 접근 및 스 핀 코팅 (spin-coating), 전기방사 (electrospinning), 핫프레싱 (hot-pressing) 등 다양한 필름 제작 방 법을 통한 공정적 접근을 이용함으로써 크게 향상 될 수 있다. 이들 방법 이외에도 PVDF 압전 고분자 에 trifluoroethylene (TrFE), hexafluoropropylene ( $\mathrm{HFP})$, chlorotrifluoroethylene (CTFE) 등 쌍극자 모 멘트 값이 높은 $\mathrm{PVDF}$ 와 구조 및 관능기가 유사한 고
분자들을 공중합하여 제작한 $\mathrm{P}(\mathrm{VDF}-\mathrm{TrFE}), \mathrm{P}(\mathrm{VDF}-$ $\mathrm{HFP}), \mathrm{P}(\mathrm{VDF}-\mathrm{CTFE})$ 공중합체를 통해 높은 압전 특성 을 확보하여 압전 고분자로 사용하기도 한다. ${ }^{13)}$

\section{2. 자왜 재료}

압전 고분자 매트릭스에 분산되어 사용되는 자왜 나 노충진재는 주로 공침법 (co-precipitation method) 와 수열합성법 (hydrothermal method)를 이용하 여 제조한다. 특히 수열합성법을 이용해 높은 결정성 과 다양한 형상을 제조할 수 있을 뿐 아니라 균일한 나 노 크기의 자왜 입자를 합성함으로써 높은 자왜 특 성 값을 확보할 수 있다. ${ }^{14-15)}$ 일반적으로 자왜 세라 믹은 스피넬 결정구조 $\left(\mathrm{AB}_{2} \mathrm{O}_{4}\right)$ 를 가지며 포화 자화 (saturation magnetization, $\mathrm{M}_{\mathrm{s}}$ ), 잔류 자화 (remnant magnetization, $\mathrm{M}_{\mathrm{r}}$ ) 및 자화 감수성 (magnetic susceptibility, $\chi_{\mathrm{m}}$ ) 등 자기적 특성이 우수하다. 특히 페라이트 기반의 자왜 세라믹 중 $\mathrm{CoFe}_{2} \mathrm{O}_{4}(\mathrm{CFO})$ 는 높 은 자기스트레인 특성 (magentostriction, $\lambda=\sim 240$ $\mathrm{ppm}$ )을 나타내기 때문에 자기전기 복합체의 자왜 재 료로 주로 사용되고 있으며, Terfenol-D, Galfenol, Metglas, $\mathrm{Fe}_{3} \mathrm{O}_{4}$ 세라믹스 외에도 니켈 $(\mathrm{Ni})$, 철 $(\mathrm{Fe})$, 코발트 (Co) 등의 자왜 특성을 지니는 금속들을 자왜 재 료로 사용한 연구들이 보고되고 있다. ${ }^{16-18)}$

\section{3. 다강성 자왜 나노충진재의 구조 개발}

자기전기 고분자 복합체로부터 높은 자기전기 출력전 압을 확보하기 위해서 압전 고분자의 베타상 분율을 높 이는 연구가 주로 진행되어왔고, 압전 고분자 내 분산된 자왜 나노충진재의 물리적 형태 및 표면 관능기의 영향 성이 많은 연구 논문에서 보고되었다. ${ }^{19-20)}$ 또한 자왜상 의 스트레인 변화가 압전상에 얼마나 효과적으로 스트 레인 전달 (strain transfer)되는가에 따라서 자기전기 출력전압의 크기에 직접적으로 영향을 미친다. ${ }^{21)}$ 이외에 도 폴링 공정에서의 누설 전류 (leakage current)의 최 소화를 통해 높은 압전특성 값을 확보함으로써 자기전 기 출력전압을 향상시키는 연구도 진행되고 있다. ${ }^{22)}$ 일 


\section{특 집 ㅁㅃ 백근렬, 양수철}

반적으로 $\mathrm{PVDF}$ 와 같은 압전 고분자의 경우 유전 물질, 즉 높은 전기 저항 $\left(10^{14} \mathrm{Ohm} \cdot \mathrm{cm}\right.$ 이상 $)$ 을 지니는 반면 $\mathrm{CFO}$ 와 같은 자왜 나노입자의 경우 $10^{6} \mathrm{Ohm} \cdot \mathrm{cm}$ 의 낮 은 전기 저항을 지니기 때문에 압전 매트릭스 내에 균일 하게 분산될 경우 전기적 퍼콜레이션 임계치 (electrical percolation threshold)를 낮추는 원인이 된다. ${ }^{23-25)}$ 따 라서 폴링공정에서 자왜충진재의 크기, 함량 및 분산 정 도를 최적화 함으로써 누설 전류를 최소화 시키면서 동 시에 높은 자왜스트레인 값을 확보해야만 한다. ${ }^{26-27)}$ 최 근 자왜 나노입자의 낮은 전기 저항 문제를 해결하기 위 해 전기 저항이 높은 세라믹을 코팅한 구조인 코어-쉘 (core-shell) 나노입자 구조를 적용하는 연구도 진행되 고 있다. ${ }^{28)}$

\section{1. 다강성 자왜 나노충진재의 물리적 형상 제어}

자왜 나노충진재는 압전 고분자 상에 분산되어 압전 성을 나타내는 베타상 분율 향상에 영향을 직접적으로 미칠 뿐 아니라 압전상에 직접 스트레인을 전달하기 때 문에 자왜 나노충진재의 물리적 형태를 제어하는 연구 가 지속적으로 이루어져 왔다. ${ }^{29-30)}$ 일반적으로 수열합 성법을 통해 합성한 0 차원의 나노입자 형태를 많이 이 용해 왔으며, Lanceros-Mendez 연구 그룹은 PVDF 압전 고분자 매트릭스 내에 $\mathrm{CFO}$ 자왜 나노입자가 분 산된 자기전기 복합체를 제작하여 $41.3 \mathrm{mV} / \mathrm{cm} \cdot \mathrm{Oe}$ 의 높은 자기전기 출력전압계수 (magnetoelectric coefficient, $\left.\alpha_{\mathrm{ME}}\right)$ 을 확보하였다. ${ }^{31)}$ 하지만 비공진 주파 수 (off-resonance frequency) 대역에서 신뢰성 있는 자기전기 출력전압을 얻는 것이 쉽지 않다. 0 차원 구조 의 나노입자 외에도 1 차원 구조의 나노로드 또는 2 차원 구조의 나노시트와 같이 종횡비 (aspect ratio)가 크고 비표면적 (specific surface area)이 큰 물질을 이용하 여 PVDF 사슬의 움직임을 물리적으로 제어함으로써 베 타상 형성을 유도하는 제한 효과 (confinement effect) 를 높이는 연구가 진행되었다. ${ }^{32)} \mathrm{Kosel}$ 연구 그룹은 $\mathrm{P}(\mathrm{VDF}-\mathrm{TrFE})$ 압전 고분자 매트릭스 내에 자왜 스트 레인 값이 다른 세 가지 자왜 재료인 $\mathrm{Fe}, \mathrm{Ni}, \mathrm{Galfenol}$ 을 나노와이어 형태로 제작한 뒤 분산시킨 3-1 미립자
구조를 제작하였다. 자왜 충진재 함량에 따른 베타상 분 석 및 매트릭스 내에서 충진재 정렬에 따른 자기 이방성 (magnetic anisotropy) 특성을 분석하였고, 20wt\%의 충진재 함량에서 가장 높은 베타상 분율 및 압전상수 값 이 향상됨을 밝혔다. 특히 충진재를 자기전기 복합체 필 름과 평행한 방향으로 정렬하였을 때 자기장 인가 방향 에 따른 자기 이방성 특성이 발현되는 것을 증명하였다. 게다가 자왜 스트레인 값과 비례하는 자기전기 출력전 압 특성 값이 확인되었고, Galfenol 나노와이어를 사용 했을 때 최대 $80 \mathrm{mV} / \mathrm{cm} \cdot \mathrm{Oe}$ 의 자기전기 출력전압 값 을 확보하였다. 이는 1 차원 나노로드 구조의 자왜 나노 충진재가 동일한 방향으로 정렬될 경우 자기 이방성 특 성에 의해 0 차원 나노입자보다 우수한 자왜 특성을 지 니게 되어 최종적으로 자왜 특성과 비례하는 높은 자기 전기 출력전압을 확보할 수 있는 것을 알 수 있다. ${ }^{33)}$ 그 림 1에서 보이듯 Yang 연구 그룹은 1차원 나노로드 구 조보다 비표면적이 큰 2차원 나노시트 구조의 충진재 를 제작하기 위해 graphene oxide (GO) 표면과 층 사 이에 $\mathrm{CFO}$ 나노입자를 흡착 및 삽입시킨 2차원 자왜 충 진재를 개발하였다. 2 차원 구조의 자왜 충진재를 PVDF 압전 고분자 매트릭스에 $3 \mathrm{wt} \%$ 의 낮은 함량을 첨가하여 분산시킨 후 핫 프레싱 공정을 통한 매트릭스 내에서 2 차원 충진재의 정렬을 유도하여 $78 \%$ 의 높은 베타상 분 율을 확보하였다. 특히 2 차원 충진재의 측면 크기를 조 절함으로써 2차원 구조의 나노충진재를 통해 유발되는 제한 효과, 스트레인 전달 현상, 누설 전류 등 자기전 기 출력전압 향상에 핵심이 되는 요인들을 종합적으로 분석하였다. 최종적으로 비공진 주파수 하에서 $3 \mathrm{mV} /$ $\mathrm{cm} \cdot \mathrm{Oe}$ 의 자기전기 출력전압 특성 값을 확보하였고, $1 \mathrm{kOe}$ 이하의 약한 직류 자기장 하에서 $r^{2}=0.9992$ 의 굉장히 우수한 선형성을 통해 자기장 센서로서의 응용 가능성을 증명하였다. ${ }^{34)}$ 이처럼 나노충진재의 물리적 형 태를 제어함으로써 자기전기 출력전압을 향상할 수 있 음과 동시에 에너지 하베스팅 또는 센서 등의 다양한 응 용이 가능하다는 것을 나타낸다. 

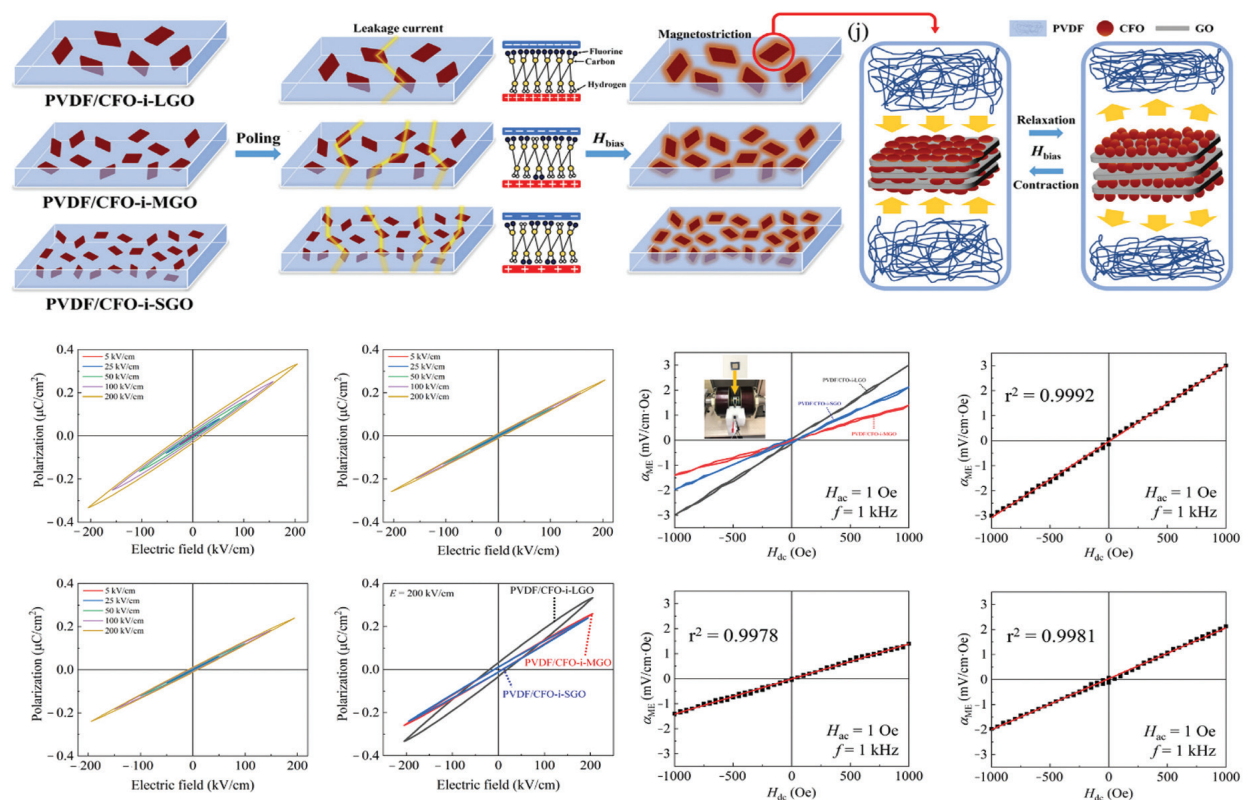

Figure 1. Polymer-based magnetoelectric (ME) particulate composite films using two-dimensional magnetostrictive fillers. Reproduced from Baek et al. Polymers 2021;13:1782, with permission of MDPI [34].

\section{2. 다강성 자왜 나노입자의 표면 전하 제어}

고분자 기반의 자기전기 복합체 연구에 있어서 자왜 나노충진재의 표면 전하 (surface charge)를 제어함으 로써 PVDF의 베타상 형성을 유도하는 연구도 꾸준히 진행되어 왔다. Lanceros-Mendez 연구 그룹은 표면 전하가 $\mathrm{PVDF}$ 의 베타상 형성에 미치는 영향에 대해 보 고하였다. 음전하를 띠는 자왜 나노 입자와 계면활성제 역할을 하는 시트르산을 이용하여 자왜 나노 입자에 표 면 처리함으로 압전 고분자 매트릭스 상에 분산시킨 결 과 양전하보다는 음전하를 띠는 자왜 충진재의 경우 상 대적으로 높은 베타상 분율을 나타내었다. 이는 강한 음 전하의 자왜 나노 입자를 충진재로 사용할 경우 압전 고 분자가 지니는 $\mathrm{C}-\mathrm{H}$ 결합과 자왜 나노 입자 표면의 음전 하와 정전기적 인력 (electrostatic interaction)을 형성 하여 베타상을 형성하게 됨을 나타내며, 양전하의 나노 입자는 압전 고분자의 $\mathrm{C}-\mathrm{F}$ 결합과 정전기적 인력이 상 대적으로 약하다는 것을 증명한 것이다. ${ }^{35)}$ 이외에도 계 면에 따른 베타상 형성에 관한 연구는 양이온, 음이온, 비이온 계면활성제를 표면 처리한 자왜 나노 입자를 이

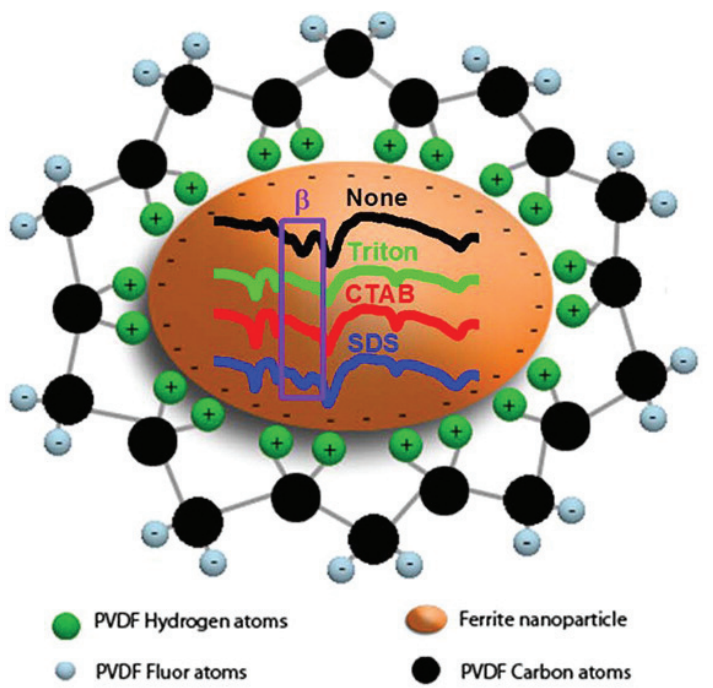

Figure 2. The mechanism of $\beta$-phase formation by electrostatic interaction between negatively charged ceramic nanoparticles and positively charged $\mathrm{C}-\mathrm{H}$ bonds in piezoelectric polymer. Adapted from Martins et al. J. Phys. Chem. C 2012;116:15790-15794, with permission of American Chemical Society [36].

용하여 메커니즘을 확인하는 방향으로 진행되어왔다. 그림 2와 같이 음전하를 띠는 자왜 나노 입자와 PVDF 
의 $\mathrm{C}-\mathrm{H}$ 결합의 정전기적 인력에 의한 베타상 형성 메커 니즘을 확인할 수 있다. ${ }^{36)}$ 따라서 자기전기 출력전압 향 상을 위해서 강한 음전하를 띠는 자왜 나노 입자를 사용 함으로써 압전 고분자의 베타상 분율을 확보하는 것이 중요하다.

\section{3. 다강성 자왜 나노입자의 코어-쉘 구조 개발}

자기전기 고분자 복합체를 구성하고 있는 압전 고분 자의 높은 베타상 분율을 확보하더라도 전기적 폴링 공 정에서 $\mathrm{C}-\mathrm{F}$ 사슬을 한 방향으로 정렬시켜주지 못한다 면 자기전기 출력전압을 확보할 수 없다. 따라서 효과 적인 폴링공정을 통해 $\mathrm{C}-\mathrm{F}$ 사슬의 정렬을 최적화하는 것이 중요하며, 자왜 나노충진재의 전기저항을 낮춰주 어 압전특성과 자기전기 출력전압을 향상시키는 연구가 진행되고 있다. 구체적으로 자왜 나노충진재 표면에 상 대적으로 높은 전기 저항을 지니는 물질을 코팅하여 코 어-쉘 구조의 자왜 충진재를 개발함으로써 고분자 기반 자기전기 복합체부터 신뢰성 있는 자기전기 출력전압을 확보한 연구가 보고되었다. ${ }^{37)}$ 또한 Zhang 연구 그룹은 $\mathrm{CFO}$ 나노입자 표면에 BTO 압전 세라믹을 코팅하여 나 노충진재의 전기 저항을 최소화하여 압전 특성을 개선 하였다. 추가로 polydopamine (PDA)를 한 번 더 코팅 함으로써 $\mathrm{PVDF} \mathrm{C}-\mathrm{H}$ 결합과 $\mathrm{PDA}$ 의 음전하를 띠는 산 소 포함 관능기와의 정전기적 인력을 통한 베타상 향상 을 통해 한층 더 향상된 유전 특성 및 압전 특성을 유도 하였으며, 최대 $150 \mathrm{mV} / \mathrm{cm} \cdot \mathrm{Oe}$ 의 자기전기 출력전압 특성을 이론적으로 계산하였다. ${ }^{38)}$ 이렇게 자왜 나노충진 재의 구조개선을 통해 고분자 복합체 내의 전기저항을 조절할 수 있고, 결과적으로 자기전기 특성을 향상시킬 수 있다.

\section{4. 자기전기 고분자 복합체 필름 제조}

자기전기 고분자 복합체 필름을 제조하기 위해서 캐 스팅, 스핀코팅, 전기방사, 핫프레싱 등과 같은 공정을 이용하고 있으며, 각각 공정에 따라 투명성, 분산성, 필 름 공극, 필름 두께 등 필름 특성이 상이하므로 응용에
따른 적절한 공정 선택이 요구되어진다.

\section{1. 캐스팅 공정}

캐스팅은 고분자 필름을 제조하는 매우 일반적인 공 정으로 닥터 블레이딩 (doctor-blading) 또는 테이프 캐스팅 (tape-casting) 이라고도 알려져 있다. 대부 분의 연구 논문에서는 압전 고분자 용액에 자왜충진재 가 분산되어 있는 자기전기 용액을 유리기판 위에 대면 적으로 얇고 균일하게 코팅한 후 용매를 증발시켜 박막 (thin film)을 제조한 후 자기전기 특성을 분석하였다. ${ }^{39}$ Zhang 연구 그룹은 캐스팅 공정 변수와 자왜 나노충진 재의 구조를 연계하여 압전 고분자의 베타상 분율을 향 상시키기는 연구를 수행하였다. 구체적으로 PVDF 압전 고분자와 $\mathrm{CFO}$ 자왜 나노입자가 분산되어 있는 용매를 유리 기판에 캐스팅한 후 용매 증발 과정에서 직류 자기 장이 인가되는 조건 하에서 용매를 증발시켰다. 직류 자 기장 인가에 의해 $\mathrm{CFO}$ 자왜 나노입자는 기계적 변형이 발생하였고, 이는 인접한 PVDF 사슬에게 인장력으로써 전달되어 $84 \%$ 의 높은 베타상 분율을 나타내었다. ${ }^{40)}$ 이 외에도 캐스팅 공정 변수 조절을 통해 고분자 사슬의 제 한 효과를 극대화하는 연구는 꾸준히 진행되고 있다. ${ }^{41)}$

\section{2. 스핀코팅 공정}

자기전기 고분자 복합체 제조에 이용되는 공정 중 하 나인 스핀코팅은 딱딱한 기판 위에 자기전기 용액의 일 정량을 드랍 후 높은 RPM으로 회전시켜 기판 전체에 균일하고 얇은 박막을 형성할 수 있는 공정이다. 스핀 코팅 공정 중 강한 원심력을 통해 자기전기 고분자 복 합체 용액 내 압전 고분자 사슬의 연신 (stretching) 효 과를 극대화시켜 높은 베타상 형성을 유도할 수 있다. ${ }^{42)}$ Lanceros-Mendez 연구 그룹은 PVDF/DMF 고분자 용액의 점도 및 $\mathrm{RPM}$ 을 조절에 따른 $\mathrm{PVDF}$ 베타상 분율 을 연구했으며, 용액의 농도가 증가할수록 필름 두께는 최대 $45 \mu \mathrm{m}$ 까지 증가하고 $10 \mathrm{wt} \%$ 의 가장 낮은 용액 농 도를 $8000 \mathrm{RPM}$ 의 회전 속도에서 스핀코팅 하였을 때 거의 $100 \%$ 에 육박하는 매우 높은 베타상 분율을 나타 냄을 보여주었다. 이는 용액의 점도가 증가하여 $\mathrm{PVDF}$ 
의 사슬 이동성이 감소하게 되어 필름 두께 증가와 함께 원심력에 의한 사슬의 연신 효과 감소에 따른 베타상 형 성 약화로 이어졌고, 반대로 용액 농도가 감소할수록 사 슬 연신 효과의 극대화로 인한 높은 베타상 형성이 가능 하다는 것을 증명하였다. ${ }^{43)}$ 하지만 나노충진재가 포함된 자기전기 용액을 사용할 경우 강한 원심력에 의해 나노 충진재가 기판의 가장자리에 위치할 가능성이 높고 복 합체 내의 불균일한 분산을 유발할 수 있으므로 회전 속 도의 최적화가 요구된다.

\section{3. 전기방사 공정}

자기전기 복합체를 제조하는데 있어서 전기방사 공정 은 전기장을 인가하면서 자기전기 용액을 방사함으로 써 섬유 형태의 나노파이버 (nanofiber)를 적층하여 다 공성 필름 형태로 제조한다. 점도를 지닌 고분자 용액 이 적절한 방사 속도와 전기장 세기 하에서 방사될 경 우 고분자 사슬 간의 얽힘 효과가 작용하여 나노파이버 구조를 형성하며, 사슬의 연신 효과와 함께 전기장 인 가에 의한 용액 내에서 고분자의 쌍극자 정렬이 발생 하여 높은 베타상 분율과 쌍극자 정렬을 동시에 성취 할 수 있다는 장점을 지닌다. ${ }^{44)}$ Kalarikkal 연구 그룹 은 $\mathrm{P}(\mathrm{VDF}-\mathrm{HFP})$ 압전 고분자에 $\mathrm{NFO}$ 자왜 나노입자와 Clay 나노시트를 복합화한 나노파이버 구조의 자기전 기 복합체 필름을 전기방사를 통하여 제작하였고, 음전 하를 띠는 표면적이 큰 Clay 나노시트의 베타상 유도 효 과를 유도하여 최대 $17 \mathrm{mV} / \mathrm{cm} \cdot \mathrm{Oe}$ 의 출력전압을 보여 주었다. ${ }^{45)}$ 이러한 전기방사 공정으로 제작된 나노파이 버 구조는 표면적이 넓기 때문에 에너지와 센서 분야뿐 만 아니라 오일 흡착 (oil adsorption) 및 미세먼지 여과 (particulate matter filtration) 등 환경 분야 등 넓은 분야에서 응용되고 있다. ${ }^{46-49)}$

\section{4. 핫프레싱 공정}

고분자 용액을 캐스팅 공정을 이용하여 고분자 필름 으로 제작한 후 열과 압력을 가해 고분자의 재결정화를 유도하기 위해서 사용하는 공정으로 핫프레싱이 이용되 고 있다. 높은 결정성 및 특정 결정상을 형성하는 핫프
레싱 공정은 압전 고분자 기반의 복합체에 널리 사용되 고 있는데, 핫프레싱 공정 진행 중 압전 고분자 사슬 간 의 간격이 좁아지게 되고 $\mathrm{C}-\mathrm{H}$ 와 $\mathrm{C}-\mathrm{F}$ 결합 간의 정전 기적 인력이 마주하는 사슬 간에 작용하게 되어 베타상 형성을 유도하게 된다. 또한 높은 결정화도 (degree of crystallinity)를 확보할 수 있기 때문에 압전 특성을 크 게 향상시킬 수 있다. ${ }^{50)}$ Yang 연구 그룹은 핫프레싱을 미립자 구조가 아닌 라미네이트 구조에 적용하였는데, 그림 3에서 보이듯 압전상과 자왜상 간의 효과적인 스 트레인 전달을 위해 바인더를 사용하지 않으면서도 전 극으로 활용할 수 있도록 니켈 폼이 PVDF 필름 위아래 로 적층된 라미네이트 구조를 제작하였다. 핫프레싱을 통해 다공성 구조를 가지는 자왜상인 니켈 폼을 압전 고 분자 위아래로 일부 삽입시킴으로써 바인더 없이 자기 전기 필름을 제조하였다. 특히 전도성을 지니는 니켈 폼 자체를 전극으로 활용하여 최대 $2.27 \mathrm{mV} / \mathrm{cm} \cdot \mathrm{Oe}$ 의 자 기전기 출력전압을 $0 \mathrm{Oe}$ 의 직류 자기장에서 확보하였는 데, 이는 셀프바이어스 (self-bias) 특성으로 외부 직류 자기장 없이도 자기전기 필름으로부터 출력전압 값을 확보할 수 있는 가능성을 보여주었다. ${ }^{51)}$ 라미네이트 구 조 이외에도 핫프레싱 공정은 압전 고분자 매트릭스 내 에 분산된 1차원 나노로드 또는 2 차원 나노시트를 필름 과 평행한 방향으로 정렬하는 효과를 유도할 수 있기 때 문에 다양한 구조체에 적용될 수 있다는 장점을 가지고 있다. ${ }^{52-53)}$

\section{5. 기능성 자기전기 고분자 복합체의 응용}

고분자 기반 자기전기 복합체는 압전 세라믹 기반 복 합체에 비해 낮은 자기전기 출력전압에도 불구하고 다 양한 구조 및 공정을 통해 자기전기 출력전압이 향상되 어 왔고, 에너지 분야를 비롯한 센서, 환경, 바이오 메디 컬 분야에서 응용될 수 있다. 


\section{특 집 ㅃㅃ 백근렬, 양수철}

(a)

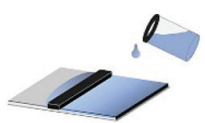

(b)

Casting

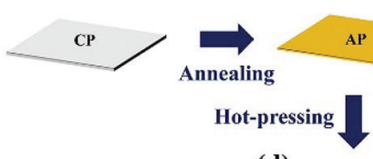

(d) (e)

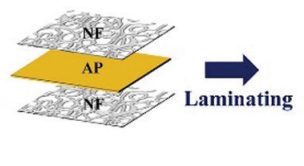

(h)

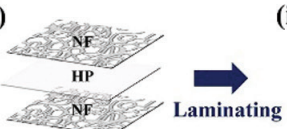

(f)

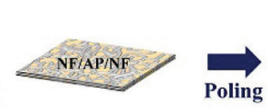

(i)

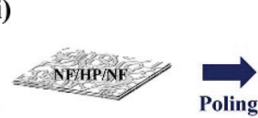

(g)

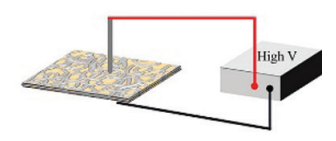

(j)

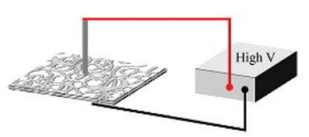

Figure 3. Polymer-based magnetoelectric (ME) laminate composites without binder fabricated by hot-pressing process. Adapted from Noh et al. J. Mater. Res. Technol. 2021;13:1266-1274, with permission of Elsevier. [51]
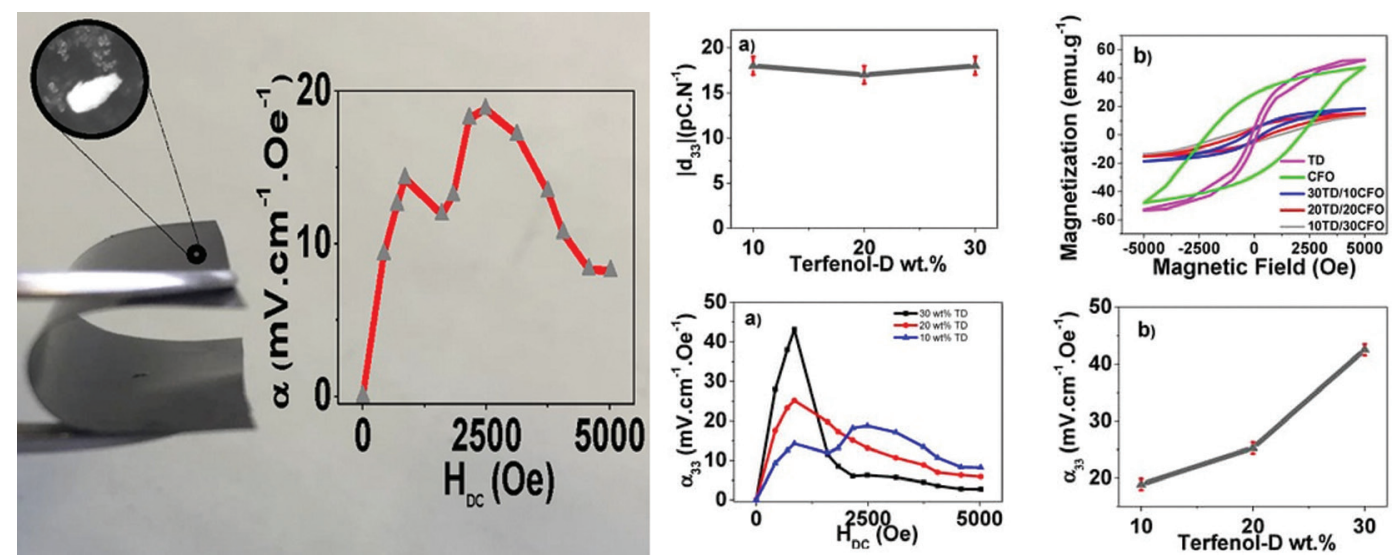

Figure 4. Polymer-based magnetoelectric (ME) particulate composite films for energy harvesting system. Reproduced from Martins et al. Polymers 2017;9:62, with permission of MDPI [54].

\section{1. 에너지 응용}

높은 자기전기 출력전압을 나타내는 고분자 복합체 필름은 에너지 하베스팅을 목적으로 이용 가능하며, 웨 어러블 디바이스로 응용할 경우 주변 자기장 변화에 의 해서만 출력전압 유도되므로 자가전원 (self-power) 으로 활용할 수 있다. 그림 4에서 보이듯 LancerosMendez 연구 그룹은 $\mathrm{P}(\mathrm{VDF}-\mathrm{TrFE})$ 압전 고분자 내의 충진재로 Terfenol-D와 $\mathrm{CFO}$ 나노입자를 함께 사용함 으로써 현재까지 보고된 미립자 구조의 자기전기 복합 체 필름 중 가장 높은 출력전압 $42.3 \mathrm{mV} / \mathrm{cm} \cdot \mathrm{Oe}$ 를 확 보하였다. ${ }^{54)}$ 이러한 높은 자기전기 출력전압 값과 함께 우수한 기계적 특성 및 비공명 주파수에서의 신뢰성 있
는 출력전압 값이 보장된다면 에너지 하베스팅 디바이 스로의 응용이 가능할 것으로 예측된다.

\section{2. 센서 응용}

플렉서블 디바이스의 요구와 함께 사물인터넷 (Internet of Things, IoT) 등 4차 산업과 연관된 기 술이 21 세기 이후로 각광받고 있다. 이러한 사물인터 넷 기술이 포함된 장비들은 전자기파를 이용하여 정보 를 주고받게 되는데, 이 때 발생하는 전자기파를 에너지 원으로 사용하여 에너지 하베스팅 및 센서로 사용하고 자 하는 연구가 관심을 끌고 있다. Mandal 연구 그룹은 $\mathrm{P}(\mathrm{VDF}-\mathrm{TrFE})$ 압전 고분자와 $\mathrm{NFO}$ 자왜 나노입자로 
구성된 미립자 구조의 롤러블 (rollable)한 자기전기 복 합체 필름을 제작하였고, 이를 이용하여 전기 주전자 및 전자레인지에서 발생하는 전자기파를 이용하여 최대 1.1 $\mathrm{V}$ 의 양진폭 전압 (peak to peak voltage, $\mathrm{V}_{\mathrm{pp}}$ )을 발생 시킬 수 있음을 증명하였다. 또한 롤러블한 자기전기 복 합체 필름은 롤링 전후로 전압값의 변화가 거의 발생하 지 않았으므로 롤러블 디바이스로의 가능성 또한 보여 주었기에 높은 기계적 특성을 바탕으로 추후 스트레처 블 (stretchable) 디바이스 개발의 기반이 될 수 있을 것 으로 판단된다. ${ }^{55}$

\section{3. 바이오 응용}

고령화 사회의 발달로 바이오메디컬 및 헬스케어 관 련 연구가 꾸준히 증가되어 오고 있는데, 자기전기 효과 를 활용한 조직 공학 (tissue-engineering) 연구에 대 한 보고가 최근 수 년간 급격히 증가하고 있다. $\mathrm{PVDF}$ 압전 고분자를 비롯한 $\mathrm{CFO}$ 자왜 나노입자 또한 생체적 합성을 지니기 때문에 인간의 골격 등에 직접적으로 접 합시킨 후에 자기전기 효과를 이용한 미세전류를 발생 시킴으로써 골격 세포의 성장 및 회복 효과를 가속화시 킬 수 있음이 증명되었다. ${ }^{56)} \mathrm{Deng}$ 연구 그룹은 $\mathrm{P}(\mathrm{VDF}-$ $\mathrm{TrFE})$ 압전 고분자 매트릭스에 $\mathrm{CFO}$ 나노입자가 분산된 미립자 구조의 자기전기 복합체 필름을 제작한 뒤, 이 를 손상된 골격 세포에 접합시킨 뒤 영구 자석을 이용하 여 직류 자기장을 인가함으로써 발생되는 자기전기 출 력전하, 즉 미세전류에 의해 동일 기간 동안 훨씬 더 빠 른 세포 회복을 보였으며, 골격 크기도 타 조건 대비 가 장 크게 증가되었음을 증명하였다. 특히 분자 동역학 시 뮬레이션을 통해 $10 \mathrm{wt} \%$ 의 자왜상 함량에서 가장 많은 수의 FN-III7-10 단백질의 흡착량을 나타내는 것을 보 여줌으로써 결과의 신뢰성을 향상시켰다. ${ }^{57)}$ 이러한 미 립자 구조 자기전기 복합체 기반의 조직 공학 이외에 도 코어-쉘 구조의 자기전기 복합체를 체내에 삽입시킨 뒤 특정 신체 부위로 이동시킨 뒤 외부 자기장을 이용하 여 약물을 방출시키는 약물 전달 시스템 (drug delivery system, DDS)와 같이 다양한 바이오메디컬 분야에서 자기전기 효과를 활용하고 있으며, 그와 관련된 연구는 계속하여 증가될 것으로 보인다. ${ }^{58)}$

\section{4. 환경 응용}

자기전기 효과는 출력전압 이외에도 출력전하를 이 용함으로써 특정 분야에 적용될 수 있다. 최근 급격 한 산업화와 도시화에 의한 문제점 중 하나로 미세먼지 (particulate matter, $\mathrm{PM}$ )에 대한 이슈가 관심을 끌고 있다. $\mathrm{PM}$ 은 대개 공장 및 차량 등에서 발생되며, $10 \mu \mathrm{m}$ 이하로 크기가 매우 작아 공기 중에 쉽게 떠다닐 수 있 는데, 이러한 $\mathrm{PM}$ 이 체내에 침투될 경우 호흡기 및 심혈 관 질환을 유발하는 등 인간의 건강에 위협을 줄 수 있 어 $\mathrm{PM}$ 을 효과적으로 제거 및 포집할 수 있는 필터의 개 발이 강력히 요구되어 왔다. 필터의 공극도 및 공극 크 기를 줄일 경우 필터 효율은 증가하게 되지만, 공기의 흐름 저항을 증가시켜 압력 강하를 증가시키게 되고, 이 는 곧 에너지 소모의 증가로 이어졌다. ${ }^{59)}$ 이를 보완하 기 위해 정전기적 인력을 이용하는 $\mathrm{PM}$ 필터를 개발하 는 연구가 진행되어 왔다. 그림 5에서 보이듯 Yang 연 구 그룹은 전기방사를 활용하여 $\mathrm{PVDF}$ 압전 고분자와 $\mathrm{CFO}$ 자왜 나노입자로 구성된 나노파이버 구조의 자기 전기 복합체 필름을 제작하였고, 이를 처음으로 $\mathrm{PM}$ 필 터에 응용함으로써 환경 분야로의 응용 가능성을 증명 하였다. 직류 자기장과 교류 자기장이 결합된 바이어스 자기장을 요구하는 자기전기 출력전압 메커니즘과 달리 직류 자기장만을 인가하여 자기전기 출력전하를 유도하 기 때문에, 외부 영구자석을 이용하여 $\mathrm{PM}$ 을 효과적으 로 포집할 수 있는 마스크로의 활용 가능성을 보여주었 다. ${ }^{[49]}$ 이는 자기전기 효과가 처음으로 환경 분야에 적용 되었다는 것과 다공성 구조의 자기전기 복합체를 이용 함으로써 $\mathrm{PM}$ 필터 이외에도 오일 흡착 기반의 수질 정 화 (water remediation)와 같은 다른 환경 분야에도 접 목할 수 있음을 서술하기에 큰 의미가 있다. 


\section{특 집 부 백근렬, 양수철}
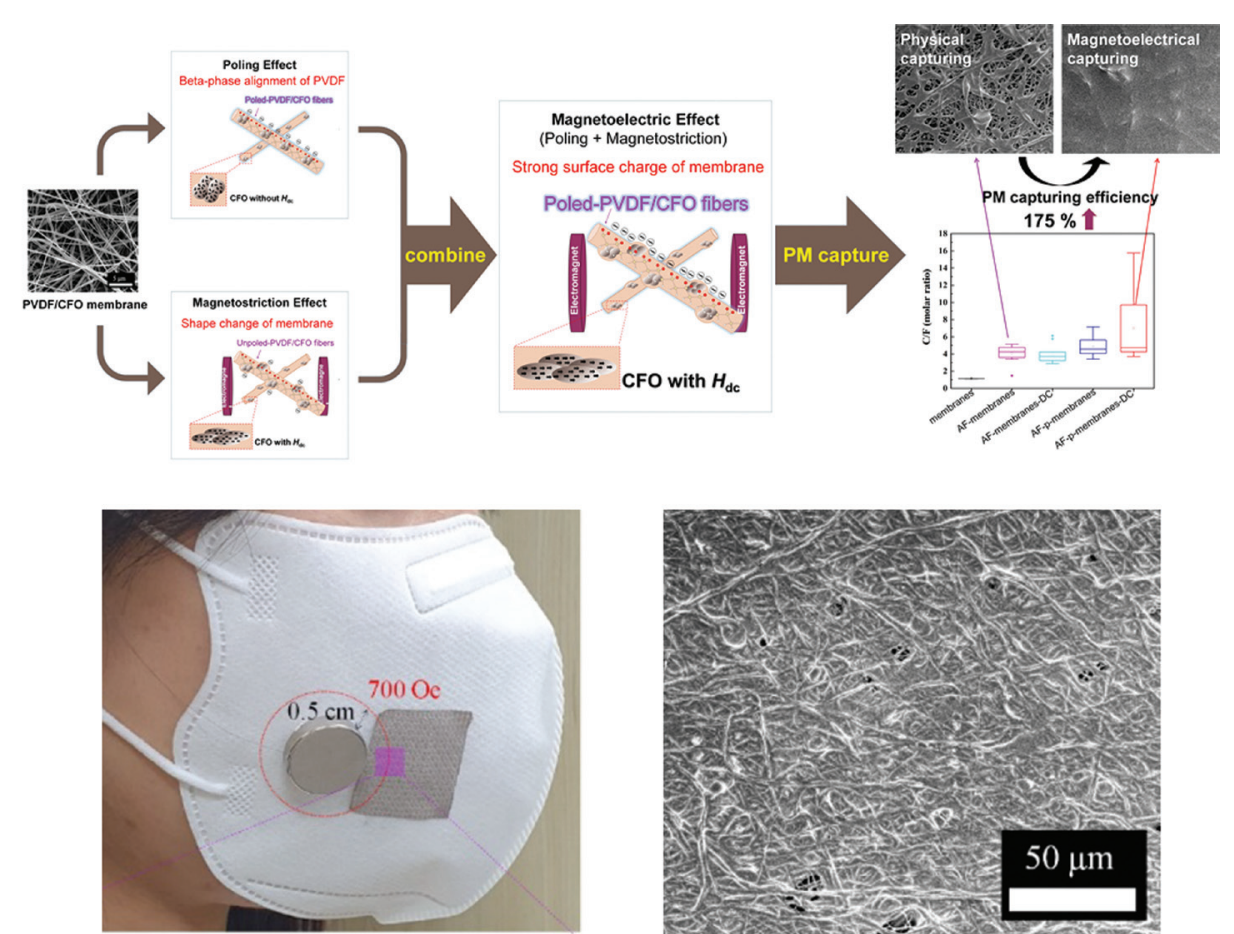

Figure 5. Polymer-based magnetoelectric (ME) nanofibrous membranes for particulate matter filtration. Reproduced from Ko et al. Polymers 2020;12:2601, with permission of MDPI [49].

\section{6. 결론}

본 리뷰 논문에서는 다강성 자왜 나노충진재가 포함 된 자기전기 고분자 복합체에 대한 간단한 역사와 자기 전기 고분자 복합체 제작을 위한 압전 고분자 및 자왜 세라믹 재료 개발, 자왜 나노충진재 구조 개발, 자기전 기 복합체 제조 공정 선택을 순차적으로 소개하였다. 또 한 자기전기 복합체의 높은 자기전기 출력전압과 유연 성 등을 이용한 에너지 하베스팅, 고감도 센서, 바이오 메디컬, 환경 분야 등 광범위한 분야에서의 응용 현황을 서술하였다. 이러한 고분자 기반 자기전기 복합체는 빅 데이터, 인공지능, 3 차원 프린팅, 나노기술 등 4 차 산업 의 핵심 기술과 밀접한 관련이 있으므로, 이들 기술과 융합화 함으로써 미래지향적인 자가 전원 디바이스를 위한 선도 기술로 자리매김할 수 있을 것으로 예상된다.

\section{REFERENCES}

1. J. Ma, J. Hu, Z. Li, and C. W. Nan, "Recent Progress in Multiferroic Magnetoelectric Composites: from Bulk to Thin Films," Adv. Mater., 23 [9] 1062-1087 (2011).

2. C. Ederer, and N. A. Spaldin, "Weak ferromagnetism and magnetoelectric coupling in bismuth ferrite," Phys. Rev. B., 71 [6] 060401 (2005).

3. P. Borisov, A. Hochstrat, X. Chen, W. Kleemann, and C. Binek, "Magnetoelectric Switching of Exchange Bias," Phys. Rev. Lett., 94 [11] 117203 (2005).

4. Y. Wang, J. Hu, Y. Lin, and C. W. Nan, "Multiferroic magnetoelectric composite nanostructures," $N P G$ Asia Mater., 2 [2] 61-68 (2010)

5. W. S. Kang, C. H. Hong, Y. J. Lee, G. Choi, D. J. Shin, D. H. Lim, S. J. Jeong, and W. Jo, "Effect of Electric Field Concentration by Electrode Patterning on the Incipient Piezoelectric Strain Properties of Lead-Free Piezoceramics," J. Korean Ceram. Soc., 56 [6] 549-557 (2019). 
6. W. Q. Liao, Y. Y. Tang, P. F. Li, Y. M. You, and R. G. Xiong, "Large Piezoelectric Effect in a Lead-Free Molecular Ferroelectric Thin Film," J. Am. Chem. Soc., 139 [49] 18071-18077 (2017).

7. D. K. Pradhan, S. Kumari, and P. D. Rack, "Magnetoelectric Composites: Applications, Coupling Mechanisms, and Future Directions," Nanomaterials, 10 [10] 2072 (2020).

8. J. Ryu, S. Priya, K. Uchino, H. E. Kim, and D. Viehland, "High Magnetoelectric Properties in $0.68 \mathrm{~Pb}\left(\mathrm{Mg}_{1 / 3} \mathrm{Nb}_{2 / 3}\right) \mathrm{O}_{3}-0.32 \mathrm{PbTiO}_{3}$ Single Crystal and Terfenol-D Laminate Composites," J. Korean Ceram. Soc., 39 [9] 813-817 (2002).

9. M. H. Choi, and S. C. Yang, " $\mathrm{CoFe}_{2} \mathrm{O}_{4}$ nanofiller effect on $\beta$-phase formation of PVDF matrix for polymer-based magnetoelectric composites," Mater. Lett., 23 73-77 (2018).

10. C. Wan, and C. R. Bowen, "Multiscale-structuring of polyvinylidene fluoride for energy harvesting: the impact of molecular-, micro-, and macro-structure," J. Mater. Chem. A, 5 [7] 3091-3128 (2017).

11. E. S. Kadir, R. N. Gayen, R. Paul, and S. Biswas, "Interfacial effects on ferroelectric and dielectric properties of GO reinforced free-standing and flexible PVDF/ZnO composite membranes: Bias dependent impedance spectroscopy," J. Alloys Compd., 843155974 (2020).

12. X. Cai, T. Lei, D. Sun, and L. Lin, “A critical analysis of the $\alpha, \beta$, and $\gamma$ phases in poly(vinylidene fluoride) using FTIR," RSC Adv., 7 [25] 15382-15389 (2017).

13. P. Martins, A. C. Lopes, and S. Lanceros-Mendez, "Electroactive phases of poly(vinylidene fluoride): Determination, processing and applications," Prog. Polym. Sci., 39 [4] 683-706 (2014).

14. J. Wang, T. Deng, Y. Lin, C. Yang, and W. Zhan, "Synthesis and characterization of $\mathrm{CoFe}_{2} \mathrm{O}_{4}$ magnetic particles prepared by co-precipitation method: Effect of mixture procedures of initial solution," J. Alloys Compd., 450 [1-2] 532-539 (2008).

15. S. Jovanovic, M. Spreitzer, M. Otonicar, J. H. Jeon, and D. Suvorov, " $\mathrm{pH}$ control of magnetic properties in precipitation-hydrothermal-derived $\mathrm{CoFe}_{2} \mathrm{O}_{4}$, , J. Alloys Compd., 598 271-277 (2014).

16. T. Lafont, L. Gimeno, J. Delamare, G. A. Lebedev,
D. I. Zakharov, B. Viala, O. Cugat, N. Galopin, L. Garbuio, and O. Geoffroy, "Magnetostrictivepiezoelectric composite structures for energy harvesting," J. Micromech. Microeng., 22 [9] 094009 (2012).

17. M. Atif, M. Nadeem, R. Grossinger, and R. Sato Turtelli, "Studies on the magnetic, magnetostrictive and electrical properties of sol-gel synthesized $\mathrm{Zn}$ doped nickel ferrite," J. Alloys Compd., 509 [18] 5720-5724 (2011).

18. S. C. Yang, C. W. Ahn, K. H. Cho, and S. Priya, "Self-Bias Response of Lead-Free (1-x)[0.948 $\left.\mathrm{K}_{0.5} \mathrm{Na}_{0.5} \mathrm{NbO}_{3}-0.052 \mathrm{LiSbO}_{3}\right]-\mathrm{xNi}_{0.8} \mathrm{Zn}_{0.2} \mathrm{Fe}_{2} \mathrm{O}_{4}$-Nickel Magnetoelectric Laminate Composites," J. Am. Ceram. Soc., 94 [11] 3889-3899 (2011).

19. M. S. Sebastian, A. Larrea, R. Goncalves, T. Alejo, J. L. Vilas, V. Sebastian, P. Martins, and S. Lanceros-Mendez, "Understanding nucleation of the electroactive $\beta$-phase of poly(vinylidene fluoride) by nanostructures," $R S C A d v$., 6 [114] 113007-113015 (2016).

20. A. Sasmal, A. Patra, P. S. Devi, and S. Sen, "Hydroxylate $\mathrm{BiFeO}_{3}$ as efficient fillers in poly(vinylidene fluoride) for flexible dielectric, ferroelectric, energy storage and mechanical energy harvesting application," Dalton Trans., 50 [5] 18241837 (2021).

21. Y. Zong, Z. Yue, P. Martins, J. Zhuang, Y. Du, S. Lanceros-Mendez, and M. J. Higgins, "Magnetoelectric coupling in nanoscale 0-1 connectivity," Nanoscale, 10 [36] 17370-17377 (2018).

22. B. P. Mandal, K. Vasundhara, E. Abdelhamid, G. Lawes, H. G. Salunke, and A. K. Tyagi, "Improvement of Magnetodielectric Coupling by Surface Functionalization of Nickel Nanoparticles in Ni and Polyvinylidene Fluoride Nanohybrids," J. Phys. Chem. C, 118 [36] 20819-20825 (2014).

23. R. Ram, M. Rahaman, and D. Khastgir, "Electrical properties of polyvinylidene fluoride (PVDF)/ multi-walled carbon nanotube (MWCNT) semitransparent composites: Modelling of DC conductivity," Compos. Part A Appl. Sci. Manuf., 69 30-39 (2015).

24. P. Martins, R. Goncalves, S. Lanceros-Mendez, A. Lasheras, J. Gutierrez, and J. M. Barandiaran, 
"Effect of filler dispersion and dispersion method on the piezoelectric and magnetoelectric response of $\mathrm{CoFe}_{2} \mathrm{O}_{4} / \mathrm{P}(\mathrm{VDF}-\mathrm{TrFE})$ nanocomposites," Appl. Surf. Sci., 313 215-219 (2014).

25. F. D. Ma, Y. M. Jin, Y. U. Wang, S. L. Kampe, and S. Dong, "Phase field modeling and simulation of particulate magnetoelectric composites: Effects of connectivity, conductivity, poling and bias field," Acta Mater, 70 45-55 (2014).

26. Q. Q Zhang, H. L. W. Chan, and C. L. Choy, "Dielectric and pyroelectric properties of P(VDFTrFE) and PCLT-P(VDF-TrFE) 0-3 nanocomposite films," Compos. Part A Appl. Sci. Manuf., 30 [2] 163-167 (1999).

27. H. L. W. Chan, Z. Zhao, K. W. Kwok, C. L. Choy, C. Alquie, C. Boue, and J. Lewiner, "Polarization of thick polyvinylidene fluoride/trifluoroethylene copolymer films," J. Appl. Phys., 80 [7] 3982 (1996).

28. L. Zhou, Q. Fu, D. Zhou, Z. Zheng, Y. Hu, W. Luo, Y. Tian, C. Wang, F. Xue, and X. Tang, "Selfassembled core-shell $\mathrm{CoFe}_{2} \mathrm{O}_{4} @ \mathrm{BaTiO}_{3}$ particles loaded P(VDF-HFP) flexible films with excellent magneto-electric effects," Appl. Phys. Lett., 111 [3] 032903 (2017).

29. P. Martins, A. Larrea, R. Goncalves, G. Botelho, E. V. Ramana, S. K. Menidratta, V. Sebastian, and S. Lanceros-Mendez, "Novel Anisotropic Magnetoelectric Effect on $\delta$-FeO(OH)/P(VDFTrFE) Multiferroic Composites," ACS Appl. Mater. Interfaces, 7 [21] 11224-11229 (2015).

30. R. Goncalves, A. Larrea, T. Zheng, M. J. Higgins, V. Sebastian, S. Lanceros-Mendez, and P. Martins, "Synthesis of highly magnetostrictive nanostructures and their application in a polymerbased magnetoelectric sensing device," Eur. Polym. J., 84 685-692 (2016).

31. P. Martins, A. Lasheras, J. Gutierrez, J. M. Barandiaran, I. Orue, and S. Lanceros-Mendez, "Optimizing piezoelectric and magnetoelectric responses on $\mathrm{CoFe}_{2} \mathrm{O}_{4} / \mathrm{P}$ (VDF-TrFE) nanocomposites," J. Phys. D: Appl. Phys., 44 [49] 495303 (2011).

32. M. M. Fernandes, H. Mora, E. D. Barriga-Castro, C. Luna, R. Mendoza-Resendez, C. Ribeiro, S. Lanceros-Mendez, and P. Martins, "Improving
Magnetoelectric Contactless Sensing and Actuation through Anisotropic Nanostructures," J. Phys. Chem. C, 122 [33] 19189-19196 (2018).

33. M. Y. Alnassar, Y. P. Ivanov, and J. Kosel, "Flexible Magnetoelectric Nanocomposites with Tunable Properties," Adv. Electron. Mater., 2 [6] 1600081 (2016).

34. G. Baek, and S. C. Yang, "Effect of the TwoDimensional Magnetostrictive Fillers of $\mathrm{CoFe}_{2} \mathrm{O}_{4}$ Intercalated Graphene Oxide Sheets in 3-2 Type Poly(vinylidene fluoride)-Based Magnetoelectric Films," Polymers, 13 [11] 1782 (2021).

35. P. Martins, C. M. Costa, M. Benelmekki, G. Botelho, and S. Lanceros-Mendez, "On the origin of the electroactive poly(vinylidene fluoride) $\beta$-phase nucleation by ferrite nanoparticles via surface electrostatic interactions," CrysEngComm, 14 [8] 2807-2811 (2012).

36. P. Martins, C. Caparros, R. Goncalves, P. M. Martins, M. Benelmekki, G. Botelho, and S. Lanceros-Mendez, "Role of Nanoparticle Surface Charge on the Nucleation of the Electroactive $\beta$-Poly(vinylidene fluoride) Nanocomposites for Sensor and Actuator Applications," J. Phys. Chem. C, 116 [29] 15790-15794 (2012).

37. G. Srinivasan, G. Sreenivasulu, C, Benoit, V. M. Petrov, and F. Chavez, "Magnetic field directed assembly of superstructures of ferrite-ferroelectric core-shell nanoparticles and studies on magnetoelectric interactions," J. Appl. Phys., 117 [17] 17B904 (2015).

38. W. Xia, J. Zhou, T. Hu, P. Ren, G. Zhu, Y. Yin, J. Li, and Z. Zhang, "Enhanced magnetoelectric coefficient and interfacial compatibility by constructing a threephase CFO@BT@PDA/P(VDF-TrFE) core-shell nanocomposite," Compos. Part A Appl. Sci. Manuf., 131105805 (2020).

39. H. Horibe, Y. Sasaki, H. Oshiro, Y. Hosokawa, A. Kono, S. Takahashi, and T. Nishiyama, "Quantification of the solvent evaporation rate during the production of three PVDF crystalline structure types by solvent casting," Polym. J., 46 [2] 104-110 (2014).

40. S. Jiang, H. Wan, H. Liu, Y. Zeng, J. Liu, Y. Wu, and G. Zhang, "High $\beta$-phase content in PVDF/ $\mathrm{CoFe}_{2} \mathrm{O}_{4}$ nanocomposites induced by DC magnetic 
fields," Appl. Phys. Lett., 109 [10] 154-158 (2016).

41. T. Prabhakaran, and J. Hemalatha, "Magnetoelectric investigations on poly(vinylidene fluoride) $/ \mathrm{NiFe}_{2} \mathrm{O}_{4}$ flexible films fabricated through a solution casting method," RSC Adv., 6 [90] 86880-86888 (2016).

42. H. Shaik, S. N. Rachith, K. J. Rudresh, A. S. Sheik, K. H. T. Raman, P. Kondaiah, and G. M. Rao, "Towards $\beta$-phase formation probability in spin coated PVDF thin film," J. Polym Res., 24 [3] 35 (2017).

43. V. F. Cardoso, G. Minas, C. M. Costa, C. J. Tavares, and S. Lanceros-Mendez, "Micro and nanofilms of poly(vinylidene fluoride) with controlled thickness, morphology and electroactive crystalline phase for sensor and actuator applications," Smart Mater. Struct., 20 [8] 087002 (2011).

44. Z. He, F. Rault, M. Lewandowski, E. Mohsenzadeh, and F. Salaun, "Electrospun PVDF Nanofibers for Piezoelectric Applications: A Review of the Influence of Electrospinning Parameters on the $\beta$ Phase and Crystallinity Enhancement," Polymers, 13 [2] 174 (2021).

45. S. K. Chacko, M. T. Rahul, B. Raneesh, and N. Kalarikkal, "Enhanced magnetoelectric coupling and dielectric constant in flexible ternary composite electrospun fibers of PVDF-HFP loaded with nanoclay and $\mathrm{NiFe}_{2} \mathrm{O}_{4}$ nanoparticles," New J. Chem., 44 [26] 11356-11364 (2020).

46. Y. Feng, Y. Zhang, J. Sheng, T. Zhang, Q. Chi, Q. Chen, and W. Fei, "Multiferroic Properties of Magnetic Anisotropy in $\mathrm{P}(\mathrm{VDF}-\mathrm{TrFE})$ Composites with Oriented $\mathrm{CoFe}_{2} \mathrm{O}_{4}$ Nanofibers," J. Phys. Chem. C., 125 [16] 8840-8852 (2021).

47. T. Zheng, Z. Yue, G. G. Wallace, Y. Du, P. Martins, S. Lanceros-Mendez, and M. J. Higgins, "Local probing of magnetoelectric properties of $\mathrm{PVDF} /$ $\mathrm{Fe}_{3} \mathrm{O}_{4}$ electrospun nanofibers by piezoresponse force microscopy," Nanotechnology, 28 [6] 065707 (2017).

48. T. Zhang, C. Xiao, J. Zhao, X. Liu, D. Ji, and H. Zhang, "One-step facile fabrication of PVDF/ graphene composite nanofibrous membrane with enhanced oil affinity for highly efficient gravitydriven emulsified oil/water separation and selective oil adsorption," Sep. Purif. Technol., 254117576 (2021).
49. K. Ko, and S. C. Yang, "Magnetoelectric Membrane Filters of Poly(vinylidene fluoride)/Cobalt Ferrite Oxide for Effective Capturing of Particulate Matter," Polymers, 12 [11] 2601 (2020).

50. J. H. Bae, and S. H. Chang, "Characterization of an electroactive polymer P(VDF-TrFE) filmtype sensor for health monitoring of composite structures," Compos. Struct., 131 1090-1098 (2015).

51. B. I. Noh, and S. C. Yang, "Polymer conformationdependent piezoelectric properties and self-bias magnetoelectric responses in adhesive-free laminate composites of Ni-foam/PVDF/Ni-foam," J. Mater. Res. Technol., 13 1266-1274 (2021).

52. Q. Chi, T. Ma, Y. Zhang, Q. Chen, C. Zhang, Y. Chi, T. Zhang, J. Lin, X. Wang, and Q. Lei, "Excellent Energy Storage of Sandwich-Structured PVDF-Based Composite at Low Electric Field by Introduction of the Hybrid $\mathrm{CoFe}_{2} \mathrm{O}_{4} @ \mathrm{BZT}-\mathrm{BCT}$ Nanofibers," ACS Sustain. Chem. Eng., 6 [1] 403412 (2018).

53. X. J. Zhang, G. S. Wang, W. Q. Cao, Y. Z. Wei, M. S. Cao, and L. Guo, "Fabrication of multifunctional PVDF/RGO composites via a simple thermal reduction process and their enhanced electromagnetic wave adsorption and dielectric properties," RSC Adv., 4 [38] 19594-19601 (2014).

54. P. Martins, M. Silva, S. Reis, N. Pereira, H. Amorin, and S. Lanceros-Mendez, "Wide-Range Magnetoelectric Response on Hybrid Polymer Composites Based on Filler Type and Content," Polymers, 9 [2] 62 (2017).

55. S. K. Ghosh, K. Roy, H. K. Mishra, M. R. Sahoo, B. Mahanty, P. N. Vishwakarma, and D. Mandal, "Rollable Magnetoelectric Energy Harvester as a Wireless IoT Sensor," ACS Sustain. Chem. Eng., 8 [2] 864-873 (2020).

56. C. Ribeiro, V. Correia, P. Martins, F. M. Gama, and S. Lanceros-Mendez, "Proving the suitability of magnetoelectric stimuli for tissue engineering applications," Colloids Surf. B, 140 430-436 (2016).

57. W. Liu, F. Zhang, Y. Yan, C. Zhang, H. Zhao, B. C. Heng, Y. Huang, Y. Shen, J. Zhang, L. Chen, $\mathrm{X}$. Wen, and X. Deng, "Remote Tuning of BuiltIn Magnetoelectric Microenvironment to Promote Bone Regeneration by Modulating Cellular Exposure to Arginylglycylaspartic Acid Peptide," Adv. Funct. 


\section{특 집 ㅃㅃ 백근렬, 양수철}

Mater, 31 [6] 2006226 (2020).

58. H. Abdelazim, "Magneto-electric nanocarriers for drug delivery: An overview," J. Drug Deliv. Sci. Technol., 37 46-50 (2017).

\section{ㅇㅇㅇㅇㅇ 수 철}

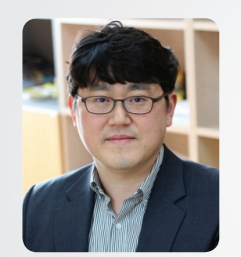

(2) 2012년 미국 버지니아공대 재료공학과 박사

( 2013년 삼성전자 반도체연구소 책임연구원

○ 2015년 동아대학교 화학공학과 부교수
59. S. Han, J. Kim, and S. H. Ko, "Advances in air filtration technologies: structure-based and interaction-based approaches," Mater. Today Adv., 9 100134 (2021).

\section{○○백 근 렬}

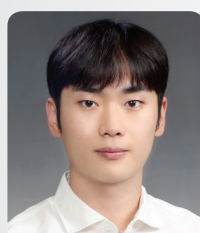

(0) 2021년 동아대학교 화학공학과 공학사 